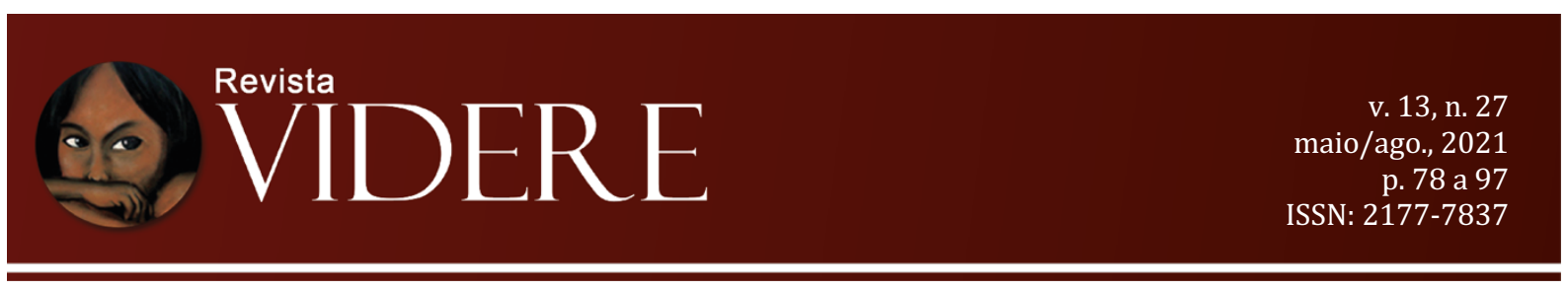

\title{
A TEORIA DOS LEILÕES E O NOVO MARCO REGULATÓRIO DO SANEAMENTO BÁSICO BRASILEIRO
}

\author{
AUCTION THEORY AND THE NEW REGULATORY FRAMEWORK FOR BRAZILIAN \\ BASIC SANITATION
}

\section{LA TEORÍA DE LA SUBASTA Y EL NUEVO MARCO REGULATORIO DEL SANEAMIENTO BÁSICO BRASILEÑO}

\begin{abstract}
Gustavo Ferreira Assed
Doutor em Direito pela Universidade Federal de Santa Catarina Professor de Graduação e Pós-Graduação da Faculdade de Direito de Ribeirão Preto da USP

E-mail: gustavo.assed@usp.br OrcidID: http://orcid.org/0000-0001-7543-4936
\end{abstract}

Carolina Ferreira Assed Doutora em Direito pela Pontifícia Universidade Católica de São Paulo- PUC-SP Professora de Graduação do Centro Universitário Moura Lacerda

E-mail: carol.assed@gmail.com OrcidID: http://orcid.org/0000-0001-7910-5080

Resumo: O objetivo do trabalho é analisar a relação entre a chamada teoria dos leilões e a abertura do setor de saneamento básico brasileiro a privatizações a partir do novo marco regulatório setorial, Lei n. 14.026/2020. Para isso, apresentar-se-á, inicialmente, um breve panorama da evolução das políticas de saneamento básico no Brasil, do início do chamado período de redemocratização política, marcado pela promulgação da Constituição da República Federativa do Brasil de 1988, até a adoção do novo marco regulatório de saneamento básico em 2020, enfatizando as principais mudanças abordadas por esta legislação no que tange à abertura para atuação da iniciativa privada no setor. Em seguida, abordar-se-á a teoria dos leilões, enquanto método formal para alocação de recursos baseado na competição, onde vendedor e comprador buscam o maior benefício, apresentando seus tipos e formulações. Por fim, descrever-se-á a aplicação da teoria dos leilões no setor de saneamento básico e suas vantagens no contexto de privatização do setor, a partir do caso do primeiro leilão de uma modelagem de concessão dos serviços de saneamento feita pelo Banco Nacional de Desenvolvimento Econômico (BNDES) - a da Região Metropolitana de Maceió/AL (RMM), que teve como vencedora a BRK Ambiental (da gestora de ativos canadense Brookfield).

Palavras-chave: Teoria dos leilões. saneamento básico. privatizações. regulação setorial. Lei n. 14.026/2020. 


\begin{abstract}
The objective of this paper is to analyze the relationship between the so-called auction theory and the opening of the Brazilian basic sanitation sector to privatizations based on the new sectorial regulatory framework, Law n. 14.026/2020. To this end, we will initially present a brief overview of the evolution of basic sanitation policies in Brazil, from the beginning of the so-called period of political re-democratization, marked by the promulgation of the 1988 Constitution of the Federative Republic of Brazil, until the adoption of the new regulatory framework for basic sanitation in 2020, emphasizing the main changes addressed by this legislation in terms of opening up the private sector to act in the sector. Then, we will approach the theory of auctions, as a formal method for allocating resources based on competition, where seller and buyer seek the greatest benefit, presenting their types and formulations. Finally, we will describe the application of the theory of auctions in the basic sanitation sector and its advantages in the context of privatization of the sector, based on the case of the first auction of a model for the concession of sanitation services done by the Banco Nacional de Desenvolvimento Econômico (BNDES) - that of the Região Metropolitana de Maceió/AL (RMM), whose winner was BRK Ambiental (from Canadian asset manager Brookfield).
\end{abstract}

Keywords: Auction theory. basic sanitation. privatizations. sectoral regulation. Law $\mathrm{n}$. $14.026 / 2020$.

Resumen: El objetivo de este trabajo es analizar la relación entre la llamada teoría de la subasta y la apertura del sector de saneamiento básico brasileño a las privatizaciones basadas en el nuevo marco normativo sectorial, Ley n. 14.026 / 2020. Para ello, presentaremos inicialmente un breve panorama de la evolución de las políticas de saneamiento básico en Brasil, desde el inicio del llamado período de redemocratización política, marcado por la promulgación de la Constitución de la República Federativa de Brasil de 1988, hasta la adopción del nuevo marco normativo de saneamiento básico en 2020, destacando los principales cambios que aborda esta legislación en cuanto a la apertura del sector privado para actuar en el sector. Luego, nos acercaremos a la teoría de las subastas, como método formal de asignación de recursos basado en la competencia, donde vendedor y comprador buscan el mayor beneficio, presentando sus tipos y formulaciones. Finalmente, describiremos la aplicación de la teoría de subastas en el sector de saneamiento básico y sus ventajas en el contexto de privatización del sector, con base en el caso de la primera subasta de un modelo de concesión de servicios de saneamiento realizada por el Banco. Nacional de Desenvolvimento Econômico (BNDES) - el de la Região Metropolitana de Maceió / AL (RMM), cuyo ganador fue BRK Ambiental (de la administradora de activos canadiense Brookfield).

Palabras clave: Teoría de la subasta. saneamiento básico. privatizaciones. Regulación sectorial. Ley n. 14.026/2020.

\title{
1 Introdução
}

O objetivo principal deste trabalho se volta à análise da aplicação da teoria dos leilões ao modelo de privatizações adotado pelo novo marco regulatório do saneamento básico brasileiro, Lei n. 14.026/2020. Os leilões são compreendidos como mecanismos eficientes e 
dinâmicos, utilizados para que se realize a comercialização de bens em mercados complexos, em especial, quando não existe uma referência estável de preço. As políticas de saneamento básico no Brasil, por sua vez, ganharam destaque em 2020, bem como o incentivo, através do marco legal, para atuação de entes privados sobre um setor que, até então, teve predomínio de atividade por instituições públicas.

Na primeira seção deste trabalho, analisa-se a trajetória dos debates e políticas que deram origem à Lei n. 14.026/2020, cujas novidades se contrastam com o cenário sociopolítico anterior do setor saneamento, mais especificamente, dos sistemas de água e esgotamento. A perspectiva de privatização do setor é um dos desafios trazidos pelo novo marco de saneamento básico, o que tem gerado uma série de debates e proposições, voltados à busca pelo reaquecimento da economia e a melhora da saúde pública.

Por meio de revisão da literatura sobre o tema das políticas de saneamento básico no Brasil, traça-se a sua evolução, a partir de 1988, com a Constituição da República Federativa do Brasil, num período descrito como redemocratização, passando pela década de 1990, com a tomada de protagonismo pelos Estados e Municípios sobre as políticas de saneamento, para, então, em 2007, ter-se a aprovação do marco legal de saneamento básico, a partir do qual, o desdobramento de debates e discussões, deu origem ao novo marco de saneamento básico brasileiro de 2020, a Lei n. 14.026/2020.

Na segunda seção, aborda-se a chamada teoria dos leilões, descrita como um método formal, utilizado para que sejam alocados recursos a partir de uma proposta de competição entre os agentes econômicos, na qual vendedores e compradores objetivam a obtenção do maior benefício possível. Sua relevância, não só advém da consagração do Prêmio Nobel de Economia de 2020 a seus precursores, Paul Milgrom e Robert Wilson, mas da sua aplicabilidade aos processos licitatórios num cenário de privatização setorial, como é o caso da proposta pelo novo marco regulatório do saneamento básico brasileiro. Nesse sentido, descrever-se seus tipos e formulações a partir de revisão bibliográfica na literatura econômica.

A terceira seção deste trabalho volta-se, propriamente, à aplicação da teoria dos leilões ao modelo de privatizações abordado pelo novo marco legal de saneamento básico, retomando o debate sobre a atuação da iniciativa privada no setor, bem como o papel desempenhado por Estados e Municípios e os conflitos entre os entes federativos a partir da Lei n. 11.445/2007, sob a perspectiva de conformação regulatória. Será analisado, nesse contexto, o caso do primeiro leilão de uma modelagem de concessão dos serviços de saneamento feita pelo Banco Nacional de Desenvolvimento Econômico (BNDES) - a da Região Metropolitana de 
Maceió/AL (RMM), que teve como vencedora a BRK Ambiental (da gestora de ativos canadense Brookfield).

$\mathrm{Na}$ tentativa de compensar eventuais ruídos metodológicos, busca-se cuidar ao máximo das remissões às seções anteriores para que construa a Conclusão deste trabalho a partir da retomada dos pontos aqui discutidos, realizando-se a exposição dos resultados obtidos, bem como a resolução dos objetivos estabelecidos e, propriamente, a conclusão da pesquisa.

Nesse ínterim, é necessário ressaltar que as conclusões não têm caráter impositivo, por mais que sejam seguras do ponto de vista do pesquisador que logrou a demonstração do estudo inscrito em linhas pretéritas, onde foram desenhados os posicionamentos principais, suficientes para a formulação da resposta à questão reitora e as conclusões derivadas, que buscam estabilizar o ponto de vista sobre as controvérsias periféricas que surgiram no decorrer da pesquisa, bem como se voltam à necessidade de que outros estudos, futuros, revisitem autores cujo trabalho tem muito a contribuir com o desenvolvimento científico do tema.

\section{As políticas de saneamento básico brasileiras e o novo marco regulatório setorial}

A partir da Constituição da República Federativa do Brasil 1988, um novo papel passa a ser desempenhado pelos Estados na política de saneamento. Embora o Artigo 21, XX, estabelece que é competência privativa da União instituir diretrizes para o saneamento básico, o Artigo 23 da Carta Magna, em seu inciso IX, observa a competência comum dos três entes federativos (União, Estados e Municípios) a promoção de programas de saneamento básico.

Os Estados e Municípios, a partir da norma constitucional, deixam de desempenhar a função de meros executores da política de saneamento, até então, centralizada pela União pelo Plano Nacional de Saneamento (Planasa), instituído em 1971 (MOTTA, 2004, p. 18-19); passando a assumir protagonismo na gestão e na implementação dos sistemas de água e esgotamento no país (VASQUES, 2020, p. 5-6).

Vale destacar que, a reorganização federativa adotada pela Constituição da República Federativa do Brasil de 1988, e a chegada do Município ao status de ente federal, deflagraram uma progressiva desarticulação entre as instituições, inviabilizando as propostas do Planasa. A despeito dos avanços relacionados à gestão dos recursos hídricos e dos sistemas de esgotamento, com as concessões e permissões de serviços públicos, foi dada manutenção à distribuição centralizada dos recursos do FGTS. Essa complexa estrutura institucional sofreu com as sucessivas trocas de Ministros e de funcionários do alto escalão do governo, o que prejudicou continuidade de sua implementação coordenada (ARRETCHE, 1999, p. 82-83). 
Embora, no primeiro mandato do Presidente Fernando Henrique Cardoso, não foi dada prioridade ao setor de saneamento, observados poucos avanços normativos e falta de interação entre as instituições atuantes sobre ele, como o Banco Nacional do Desenvolvimento Econômico e Social (BNDES) e a Caixa Econômica Federal; no segundo, o governo federal se reposiciona sobre a pauta, tendo em conta a crise financeira experimentada no período e, em razão dela, foram buscados empréstimos junto ao Fundo Monetário Internacional (FMI) (ARRETCHE, 1999, p. 99-100).

Na década de 1990, o Brasil passa por um período de privatizações, deflagrado por uma série de políticas neoliberais, aplicadas a diversos setores, como energia, telecomunicações e, especificamente, saneamento. Neste último caso, fracassaram as tentativas de implementação de uma agenda a partir de um marco regulatório federal diante da forte oposição articulada pela Frente Nacional pelo Saneamento Ambiental (FNSA), coordenada pela Federação Nacional dos Urbanitários (FNU) e pela Central Única dos Trabalhadores (CUT), dentre outros importantes atores sociais. No entanto, destaca-se que a Lei n. 8.987/1995, Lei de Concessão de Serviço Público, e o Programa de Modernização do Setor de Saneamento já ofereciam os elementos fundamentais para que fossem realizadas as privatizações (SOUSA; COSTA, 2011, p. 3549$3550)$.

A partir de 2003, a gestão de Luiz Inácio Lula da Silva se voltou a ampliar a participação da iniciativa privada nas políticas de saneamento básico com a condução de parcerias público-privadas (PPPs), uma alternativa encontrada para atração de investimentos no setor, tendo sido aprovada pela Lei n. 11.079/2004, que institui as normas para licitação e contratação de PPPs (NOZAKI, 2007, p. 48).

A Política Nacional de Saneamento Básico, Lei n. 11.445/2007, foi sancionada em 2007. Foi proposta reestruturação regulatória no setor, a partir do estabelecimento de orientações para articulação entre os atores e funções, priorizando a atuação dos Municípios e reconhecendo a diversidade regional do Brasil (NOZAKI, 2007, p. 56-57)

Embora tenham sido propostos incentivos à privatização do setor, ressalta-se relevante retomada do investimento público com a implementação dos Programas de Aceleração do Crescimento (PACs), que visavam estimular a participação de Estados e Municípios na agenda federal, incluindo o condicionamento da contratação de prestadores de serviços para acesso aos recursos da União e o desenvolvimento de diretivas para planejamento e execução das políticas de saneamento pelas instituições locais e regionais (SANTOS; VASQUES, 2015, p. 17811783). 
Em 2014, a crise político-financeira que assolou o Brasil, teve como principal consequência, o impeachment de Dilma Rousseff em 2016. Com isso, ressurgiu a oportunidade política para a retomada da pauta sobre as privatizações no setor de saneamento básico (VASQUES, 2020, p. 6).

Nesse cenário, Michel Temer, então Presidente, em julho de 2018, propôs a Medida Provisória N. ${ }^{\circ} 844 / 2018$, que concentrava na Agência Nacional de Águas (ANA) a competência para alteração de normas envolvendo contratos de programa, que, a partir daí, seriam submetidos a processos licitatórios, bem como para determinação de tarifas e para mudança da titularidade municipal, tal qual o subsídio cruzado e a lógica de ganhos de escala. Nesse ínterim, as disputas entre Estados e Municípios foram colocadas de lado, tendo em vista a ameaça de privatização do setor de saneamento (VASQUES, 2020, p. 6-7).

A Medida Provisória perdeu sua vigência em novembro de 2018, uma vez que não foi apreciada pelas Casas do Congresso Nacional. Seu conteúdo, porém, foi reeditado na Medida Provisória $N^{0} 868$, promulgada final do governo Temer, ficando, sua votação, para nova legislatura. Os apoiadores da medida entendiam que a nova regulamentação atrairia investimentos da iniciativa privada, possibilitando sua universalização, observados os déficits que se mostraram inatingíveis em face das limitações do uso dos recursos públicos para tal fim e o equacionamento fiscal dos Estados (VASQUES, 2020, p. 8).

Medida Provisória N. ${ }^{\circ} 868$ teve seu enunciado normativo apresentado em Projeto de Lei (PL) de autoria do Senador Tasso Jereissati (PSDB-CE), em junho de 2019, assim que venceu o prazo de vigência da Medida Provisória. O Projeto de Lei n. 3.261/2019, no mesmo mês, foi transformado em Projeto de Lei n. 4.162/2019 na Câmara dos Deputados e, nesta, foi aprovado, com a versão final do texto vedando contratos de programa.

Uma vez encaminhada para apreciação pela Câmara dos Deputados, o Projeto de Lei tramita em regime prioritário. A Câmara constitui Comissão Especial para analisar o texto que havia sido enviado pelo Senado. Em 30 de outubro de 2019, com a aprovação do relatório pela Comissão, e, depois pelas duas Casas Legislativas, em 15 de julho de 2020, o Jair Bolsonaro sanciona o novo marco legal do saneamento básico (Lei n. 14.026/2020) (GONÇALVES; DA SILVA, 2020, p. 73-74).

A Lei n. 14.026/2020, promove alterações na Lei n. 11.445/2007 ao mudar o espectro de responsabilidade dos Municípios ao impor ao ente federativo critérios para acesso aos recursos da União; facilitar a atuação da iniciativa privada no setor de financiamento, abrindo seu acesso a recursos públicos para investimento, observada a necessidade processo licitatório para concessões e a extinção de contratos precários e do contrato de programa entre as 
Prefeituras e as empresas estaduais; e direcionar o mercado rumo a uma maior autonomia financeira, observado mais peso às tarifas de recursos e à própria regulação setorial (PITASSI; FERREIRA, 2020, p. 111-112).

A Agência Nacional de Águas (ANA), nos termos do marco, se volta a um novo eixo de atuação, com atribuições delimitadas, de cunho executivo, e preceitos próprios do modelo de agências reguladoras. A ANA se apresenta como uma figura incomum na teoria da regulação, vez que sua receita não advém da atividade de mercado regulada, qual seja, o saneamento básico, a partir da gestão de recursos hídricos e dos sistemas de esgotamento (PITASSI; FERREIRA, 2020, p. 113).

\section{$2.1 \mathrm{O}$ novo marco regulatório do saneamento básico brasileiro e as privatizações}

No que tange à abertura para atuação da iniciativa privada no setor de saneamento básico alterações trazidas pelo novo marco regulatório se voltam a três questões-chave, entre as quais, estão: (1) a dinâmica da oferta de serviços em regime de monopólio, tendo em vista a concorrência na concessão; (2) o aumento do peso das tarifas, as quais, além de promoverem o custeio operacional, passam a ser fonte de investimentos de maior peso; e (3) a tese de privatização, ou venda de ativos, como mecanismo de atração de investimentos privados (SANTOS, KUWAJIMA; SANTANA, 2020, p. 47-48).

Pontua-se que os fundos públicos de financiamento são os recursos já consolidados, cuja manutenção é feita por meio de tributos que compõem a receita do orçamento geral da União, bem como de Estados e Municípios. Além disso, pontua-se que os investimentos do próprio setor são garantidos pela tarifa de serviços. Aqui, tem-se uma operacionalização em conjunto com a abertura de capital, ou com a constituição de Sociedades de Propósito Específico (SPEs), ou outras parcerias público-privadas, consórcios para novos investimentos, por exemplo (SANTOS, KUWAJIMA; SANTANA, 2020, p. 48).

No contexto da tese que sustenta que a privatização atrairia, embora tenha-se a ideia de que há maior eficiência na prestação privada do que na pública, é necessário considerar a grande parte da mão-de-obra e o regime de prestação de serviços já assumidos pela iniciativa privada, bem como obras, projetos e outros elementos de custos. Aqui, a margem de redução de custos pode não ser tão grande quanto se diz (SANTOS, KUWAJIMA; SANTANA, 2020, p. 48-49).

Questiona-se se propostas de incentivo ao investimento privado promovem ingresso de recursos provenientes de fundos diversificados, a venda de ações na bolsa de valores e a 
emissão de títulos por parte dos controladores das empresas. Neste último, destaca-se que para sustentação dos negócios, a tarifa é a forma de pagamento dos empréstimos e de remuneração, inclusive quando da criação de fundos próprios pelas instituições privadas (SANTOS, KUWAJIMA; SANTANA, 2020, p. 49).

Os problemas aqui, variam da dependência da atividade econômica local e dos patamares de emprego e renda para que os preços dos serviços não prejudiquem o bem-estar das populações, passando pela possibilidade de não aceitação dos aumentos de preços, exigindo grande capacidade inicial de investimento privado, até a dependência de sintonias entre a legislação setorial e arranjos político-administrativos complexos, envolvendo Prefeituras, Estados, agências reguladoras e outras instâncias deliberativas para que seja conferida escalabilidade (BANCO MUNDIAL, 2019, p. 3). A preocupação com a necessidade de uma gestão sustentável e integrada de saneamento permanece (WWAP, 2018, p. 136).

A efetividade dessas medidas, porém, será passível de avaliação somente com a maturação das mudanças trazidas pelo novo marco regulatório do saneamento. Nessa linha, o estimulo à privatização, ou "desestatização", decorre de medidas que não apresentam fundamentos ou capacidade para atrair financiamento diverso dos mecanismos mencionados, dependendo de apoio estatal (SANTOS, KUWAJIMA; SANTANA, 2020, p. 54).

A tese de maior eficiência da iniciativa privada é sustentada: (1) pela potencialidade de redução de recursos transferidos para salários, encargos e direitos trabalhistas; (2) pela viabilidade de diminuição do risco de interferência política, observado o pressuposto de independência regulatória; e (3) pela continuidade dos investimentos públicos em financiamentos e subsídios diretos e indiretos para regiões em situação de vulnerabilidade. A atuação da iniciativa privada não garante financiamento ou desonera o contribuinte. Da mesma forma, não é qualquer prestação de serviço público de saneamento que assegura qualidade e preço justo (SANTOS, KUWAJIMA; SANTANA, 2020, p. 56).

\section{A teoria dos leilões}

Cumpre destacar que a análise da aplicabilidade da teoria dos leilões às propostas de abertura à atuação da iniciativa privada, observadas pela Lei n. 14.026/2020, sob uma perspectiva estritamente jurídica, muito provavelmente, não seria o bastante para que se identificasse todo o sistema de incentivos que tais previsões normativas geram para os entes privados que se propõem a atuarem no setor de saneamento. Quando se fala em sistema de incentivos, o termo "incentivo", cuja utilização é cada vez mais comum em estudos jurídicos, 
consiste na apropriação de um jargão da área econômica (GIAMBIAGI, 2015, p. 213). Nesse sentido, para uma compreensão aprofundada da relação entre os temas, se faz necessário lançar mão da chamada Análise Econômica do Direito (GICO JR, 2010, p. 7-8).

Um dos métodos mais relevantes para a análise econômica das privatizações no contexto do novo marco regulatório do saneamento é a chamada teoria dos leilões. Essa ferramenta utiliza técnicas matemáticas e de teoria dos jogos para avaliar as estratégias tidas como ótimas e que deveriam ser adotadas pelo leiloeiro, no desenho do certame, ou pelos próprios ofertantes em um leilão (MATOSO, 2010, p. 475-476). Foi William Vickrey (1961), ganhador do prêmio Nobel em Economia no ano de 1996, em obra seminal sobre o tema, intitulada Counterspeculation, Auctions, and Competitive Sealed Tenders, quem reconheceu aspectos de teoria dos jogos na dinâmica dos leilões.

A teoria dos leilões apresenta importância não apenas teórica, tendo sido, novamente, colocada em pauta com a premiação de Paul Milgrom (1987) e Robert Wilson (1987) com o prêmio Nobel em Economia em 2020, como também prática. Por mais que não seja uma ferramenta recente, uma grande variedade e quantidade de bens, serviços e instrumentos financeiros são negociados através de leilões (KLEMPERER, 2004, p. 15).

Afirma-se que leilões, enquanto instrumentos de alocação de recursos, já eram utilizados na região da Babilônia centenas de anos antes da era cristã. Nesse contexto, na cultura popular são conhecidos os leilões de escravos e dos espólios de guerra realizados pelos Romanos no período imperial (KRISHNA, 2010, p. 1).

No período moderno, observa-se que essa ferramenta se difundiu ainda mais, não somente por seu uso no comércio eletrônico, como também pela abordagem em negociações de privatizações ou em novos mercados de energia, de transporte, de telefonia ou, até mesmo, de autorizações e licenças para emissão de poluentes por particulares (em quaisquer de seus níveis) (KLEMPERER, 2004, p. 9-10). Além disso, os leilões foram bastante utilizados para as concessões das licenças para exploração de internet 3G na Europa no início dos anos 2000 (BINMORE; KLEMPERER, 2002, p. C74-C75).

Destacada a importância assumida pelos leilões para a realização de transações econômicas, a sua teoria vem sendo, mais recentemente, objeto também de estudos empíricos, voltados à comprovação de seus resultados teóricos a partir da análise de dados concretos obtidos de setores econômicos relevantes (KLEMPERER, 2004, p. 9-10; DE SILVA, 2008, p. 175-179).

No que diz respeito à teoria econômica, o leilão pode ser interpretado como um jogo de incompletude de informações, no qual os jogadores, então, participantes do leilão, não sabem 
exatamente a avaliação feita pelos demais quanto ao objeto leiloado, não conhecendo com precisão, nesse sentido, a quantidade de recursos que cada um está disposto a alocar, ou obter, dependendo do posicionamento, para se consagrar vencedor da disputa (FIANI, 2015, p. 296).

Dentro da perspectiva das ciências econômicas, um processo licitatório, utilizado para a escolha de uma instituição, junto à qual, o Estado celebra um contrato de concessão, como usualmente concebido nada mais seria do que uma espécie de leilão reverso: trata-se de um procedimento em que o Estado estabelece o objeto que demanda e, após determinar as regras do leilão, recebe ofertas de particulares para o fornecimento de tal objeto, devendo optar, em termos constitucionais e legais, pela proposta mais vantajosa (FIUZA; MEDEIROS, 2015, p. $31)$.

Quando se aponta que o caso se trata de um leilão reverso, tem-se que, a despeito do leilão tradicional, aquele que promove o leilão, no caso, a Administração Pública, não está oferecendo um bem ao mercado, mas, ao contrário, está buscando receber propostas deste para que tenha o objeto demandado fornecido por outros agentes econômicos. Nesse sentido, as conclusões características da teoria dos leilões, devem ser interpretadas com a inversão da métrica de preços (SILVA, 2017, p. 11). Em termos práticos, tem-se que os resultados de maior receita (ou de maior preço) na teoria dos leilões equivalem ao menor custo (ou menor preço) nos processos licitatórios.

Nesse ínterim, não há outras distinções entre um leilão convencional, no qual o leiloeiro vende produtos, e os processos licitatórios, através dos quais o Estado, então, leiloeiro, é o demandante e os fornecedores, entes públicos e privados, os ofertantes, os quais intentam a promoção da Administração Pública a partir o objeto demandado.

Desta feita, as conclusões mais importantes da teoria dos leilões podem ser aplicadas, também, às licitações, necessárias para a contratação da iniciativa privada pelo Estado, no modelo de concessões adotado pelo novo marco regulatório do saneamento básico. Por esse motivo, a análise econômica da contratação pública deve ser feito por meio do instrumental oferecido pela teoria dos leilões.

Um dos resultados mais relevantes e fundamentais da teoria dos leilões, quando aplicada às licitações, é o chamado teorema da equivalência das receitas, que propõe, resguardadas determinadas condições ideais, que o leiloeiro virá a obter o mesmo retorno através da utilização de diferentes tipos de leilões. Através deste teorema, a teoria dos leilões é desenvolvida em análises que flexibilizam as premissas ideais assumidas, como neutralidade de risco e a própria simetria dos ofertantes, além da independência das propostas e das 
informações. Verifica-se que, em determinadas circunstâncias, um modelo de leilão traz resultados melhores do que outros (WEISHAAR, 2013, p. 42).

Correia, Lanzotti e Silva (2003, p. 711) identificam três padrões de leilões, os quais podem ter suas características combinadas entre si e dar origem a outros tipos diversos. É comum que regras sejam adicionadas, como preço de reserva, tempo máximo para realização do lance e taxa de participação. Essas variações são decorrentes das circunstâncias: (1) a partir da posição dos participantes, (2) a partir da revelação de preços, e, ainda; (3) a partir do preço de liquidação.

3.1 Leilões baseados na posição dos participantes

São três os tipos de leilões baseados na posição dos participantes: (1) o leilão duplo; (2) o leilão de oferta; e (3) o leilão de demanda (CORREIA; LANZOTTI; SILVA, 2003, p. 711-712).

O leilão duplo observa de um lado os fornecedores que ofertam um determinado bem ou serviço; e do outro lado compradores que demandam o bem ou o serviço. A negociação entre entre as partes pode ser intermediada por um terceiro, denominado, leiloeiro, ou, simplesmente, acontecer diretamente entre ambos, tendo, o leiloeiro, a sua atuação restrita à de organizador do leilão. Quando os agentes econômicos de um lado tomam conhecimento dos lances dos agentes do outro, tem-se que o leilão é de participantes identificados; em hipótese inversa, o leilão é tipo como de participantes não identificados (CORREIA; LANZOTTI; SILVA, 2003, p. 711).

No leilão de oferta, por sua vez, tem-se que apenas os vendedores podem efetuar lances, de maneira que ofertam um bem que o leiloeiro pretende comprar ou licitar. Neste tipo de leilão, o leiloeiro pode fixar um preço de reserva acima do qual o bem ou serviço não é adquirido, vencendo o agente econômico que fizer o melhor lance de oferta, no caso, o menor (CORREIA; LANZOTTI; SILVA, 2003, p. 712).

Por fim, em um leilão de demanda, tem-se que, tão somente os compradores podem efetuar lances, sendo, estes, que demandam um bem ou serviço que o leiloeiro se propõe a vender ou outorgar. O leiloeiro, aqui, pode fixar um preço de reserva abaixo do qual o bem ou serviço não é vendido, vencendo o agente econômico que fizer o lance mais alto (CORREIA; LANZOTTI; SILVA, 2003, p. 712) 
3.2 Leilões baseados na revelação de preços

Diversos dos tipos de leilões baseados na posição dos participantes, são dois os formatos de leilões baseados na revelação de preços: (1) o leilão aberto (ou inglês); e o (2) lei fechado (holandês) (KLEMPERER, 2004, p. 11).

Quando tem-se lances realizados em sequencia, através dos quais os agentes tomam conhecimento do lance dos seus adversários e cada lance é maior que o imediatamente anterior, tem-se o chamado leilão aberto (ou inglês). Nesse tipo de leilão, sai vitorioso o participante que fez o último lance, observado que, necessariamente, o preço de reserva deva ter sido atendido. Neste leilão, é permitido que o valor de oportunidade de cada participante seja confrontado com o dos demais (CORREIA; LANZOTTI; SILVA, 2003, p. 713).

Em contrapartida, no leilão fechado (ou holandês), os lances são realizados simultaneamente ao leiloeiro por meio de envelopes fechados. Ganha o agente que fizer o melhor lance, com a condição de que o preço de reserva tenha sido alcançado. Neste leilão, é exige que cada participante faça um lance, considerandom exclusivamente, seu valor de oportunidade, pois ele só terá conhecimento dos demais lances quando o leilão estiver finalizado (CORREIA; LANZOTTI; SILVA, 2003, p. 713). O leilão fechado também é conhecido como leilão silencioso.

\subsection{Leilões baseados no preço de liquidação (ou fechamento)}

Por fim, os leilões baseados no preço de liquidação, também denominado preço de fechamento, podem ser classificados como: (1) uniformes; ou (2) discriminatórios. Enquanto, no primeiro caso, tem-se que todos os participantes pagam o mesmo preço, independentemente do valor de seus lances; no segundo, cada agente faz o pagamento de acordo com as ofertas que realizou (CORREIA; LANZOTTI; SILVA, 2003, p. 713).

Dentro da classificação dos leilões uniformes, são observados dois subtipos: os leilões (a) de primeiro ou (b) de segundo preço. No primeiro caso, sai contemplado o participante que fizer o melhor lance. Neste, o preço de liquidação corresponde ao lance ganhador. No leilão de segundo preço, por sua vez, também conhecido como Vickrey, sai vitorioso o participante que fizer o melhor lance, mas o preço de fechamento corresponde ao melhor lance perdedor (CORREIA; LANZOTTI; SILVA, 2003, p. 713).

O leilão de fechamento de preços do tipo discriminatório é o mais apropriado e usual para o leiloeiro que pretende atuar como corretor, uma vez que, este, realiza a compra do bem 
ao menor preço possível e vende ao maior preço que conseguir (CORREIA; LANZOTTI; SILVA, 2003, p. 713).

\subsection{Os leilões no ordenamento jurídico brasileiro}

Observados os tipos de leilões descritos, acredita-se ser possível traçar um paralelo com tipos ou modalidades de processos licitatórios existentes no ordenamento jurídico brasileiro e tradicionalmente utilizados pela Administração Pública. O tipo menor preço, por exemplo equivale ao leilão de fechamento de preços do tipo uniforme de primeiro preço. No pregão, a primeira fase, relativa a envelopes contendo a indicação do objeto e do preço oferecidos (nos termos do Artigo 4. ${ }^{\circ}$, VII, da Lei n. 10.520/2002), também corresponde ao formato de leilão de fechamento de primeiro preço. Em contraponto, a fase seguinte de lances verbais (observada pelo Artigo 4. ${ }^{\circ}$, VIII, da Lei n. 10.520/2002) aproxima-se ao leilão aberto, ou inglês. Assim, no pregão definiu-se uma espécie leilão anglo-holandês invertido, por meio do qual, em sentido inverso do que acontece em sua definição clássica, a primeira fase ocorre com envelopes fechados e, a segunda, de modo aberto (CARVALHO, 2018, p. 182).

Nesse cenário, Fiuza e Medeiros (2015, p. 34) criticam o quadro de mais absoluta pobreza de formatos de leilões nas licitações brasileiras quando comparado com a diversidade de modelos e estudos sobre o tema existentes na literatura estrangeira (KLEMPERER, 2004; BINMORE; KLEMPERER, 2002; e FIUZA; MEDEIROS, 2015).

Os autores destacas que, antes do Regime Diferenciado de Contratação, havia no país, para a utilização mais cotidiana, apenas três modalidades com leilões silenciosos, de envelopes fechados, quais sejam (1) a concorrência, (2) a tomada de preço e (3) o convite; além de dois leilões híbridos, no caso, os pregões (1) presencial e (2) eletrônico (FIUZA; MEDEIROS, 2015, p. 35).

Não se fornece à Administração Pública, nesse sentido, a necessária flexibilidade que realize o desenho de um processo licitatório em consonância com as finalidades e valores que persegue, buscando eficiência e atendimento ao interesse público (FIUZA; MEDEIROS, 2015, p. 39).

O mais importante e relevante aprendizado transmitido pela teoria dos leilões, e que é comumente ignorado por legisladores e administradores públicos brasileiros - é que o fato de que desenho dos leilões ou dos processos licitatórios não pode ser proposto a partir de um modelo padrão, que serviria para qualquer situação, mas arquitetados de acordo com as circunstâncias particulares de cada caso (KLEMPERER, 2004, p. 4). 
Nesse sentido, a aplicação da teoria dos leilões aos processos licitatórios que abririam margem à atuação da iniciativa privada através do modelo de concessões para o setor de saneamento básico deve observar as peculiaridades setoriais, levando em conta as características próprias dos sistemas de água e esgotamento, bem como as necessidades locais e regionais emergentes.

Nesse sentido, observa-se que, o Estatuto das Estatais, por exemplo, manteve a tendência de conferir à Administração Pública maior flexibilidade na formatação dos leilões, sendo a consolidação dessa abertura normativa um dos progressos necessários para o enfrentamento da corrupção e da cartelização no contexto das privatizações setoriais. (sobre o tema, vide: CARVALHO, 2018, p. 183-198).

\section{A teoria dos leilões e as privatizações sobre o setor de saneamento básico brasileiro}

Como visto, leilões são mecanismos amplamente utilizados quando se desconhece o valor do bem negociado, fixado em razão da expectativa do mercado. Nesse sentido, a utilização de leilões em maior escala remete à problemática de melhor compreendê-los, tanto no que tange às possibilidades de formato, quanto às estratégias de participação dos agentes econômicos.

A reestruturação do setor de saneamento básico, abre margem à criação vários novos espaços de atuação da iniciativa privada, que enfatizam a potencialidade da aplicação da teoria dos leilões. Alguns dos tipos descritos neste trabalho cumpririam uma função temporária, observados os que estão cada vez mais sedimentados no mercado, ainda que outros possam ser criados, em observância às peculiaridades da prestação às necessidades locais de onde ele seria prestado.

Por meio da teoria de leilões, seria possível a obtenção de informações de sinais de preços e a elaboração um histórico de estratégias de participantes em um cenário de concorrência, como o que se pretende para o setor de saneamento no país no país. Nesse sentido, deve-se buscar a produção de informações relativas a estratégias tomadas por concorrentes no passado, que possam subsidiar bons lances em disputas futuras.

Nessa linha, os leilões podem ser formatados de acordo com a necessidade e a estratégia de concessão do serviço ou obra de saneamento. Vale, nesse contexto, apresentar o caso da Região Metropolitana de Maceió, Alagoas, que promoveu leilão sobre a concessão regionalizada dos serviços de abastecimento de água e esgoto sanitário vencido pelo Consórcio BRK Ambiental, que tem, dentre seus investidores, a canadense Brookfield. 


\subsection{O caso da Região Metropolitana de Maceió (AL)}

Realizado pelo Banco Nacional do Desenvolvimento Econômico (BNDES), ocorreu o primeiro leilão no modelo de concessão pública para serviços de saneamento básico na Região Metropolitana de Maceió, no Estado de Alagoas, em setembro de 2020, quando foi promovida a concessão de serviços de abastecimento de água e tratamento de esgoto de áreas urbanas abarcadas pelos Municípios da Região e seus entornos. Essa contratação pública se deu somada a outras duas parcerias público privadas (PPPs) já em andamento, uma Patrocinada e uma de locação de ativos, ambas, associadas ao tratamento de esgoto da capital Maceió.

Durante o prazo de vigência (trinta e cinco anos), será aportado um investimento de dois bilhões e seiscentos mil reais. Objetiva-se (i) a universalização do serviço de abastecimento de água até o sexto ano do contrato; (ii) a abrangência de $90 \%$ de atendimento de serviços de tratamento de esgoto, da coleta ao tratamento, até o décimo primeiro ano; e (ii) de $80 \%$ até o décimo sexto ano nos Municípios do entorno. Esses investimentos representariam treze vezes o montante dos feitos na área objeto de concessão desde o ano de 2007 (GONÇALVES et. al., 2020).

A licitação realizada por meio de leilão recebe visibilidade na medida em que foram realizadas sete ofertas com ágios acima de $1000 \%$, tendo, os quatro maiores lances, valores superiores a um bilhão de reais. Também chama atenção o interesse de entidades que não teriam a cultura empresarial associada a atuação no setor de saneamento, o que demonstra a diversidade de investidores que foram atraídos a partir da abertura do setor. Nesse contexto, a participação da Companhia de Saneamento Básico do Estado de São Paulo (SABESP) evidencia o interesse da sociedade de economia mista de atuar para além das fronteiras do seu Estado de origem (AGUIAR, 2020).

A despeito do destaque e relevância do leilão em pauta, problematiza-se seu valor de outorga ter sido muito elevado quando comparado à projeção do BNDES (cerca de quinze milhões e cem mil reais), observado o seu potencial de refletir mais a capacidade de negociação do vitorioso do que, propriamente, a eficiência do serviço que poderá vir a prestar (GONÇALVES et. al., 2020). Chama-se essa conduta negocial de winner's curse, ou, em tradução literal, "maldição do vencedor". Ela se dá quando, ainda que ofereça um lance que lhe garanta vitória, em razão da sua capacidade negocial ou mesmo da potencial influência que exerça sobre o regulador do serviço, o participante do leilão não consiga banca-la, levantando uma expectativa de renegociação do contrato após determinado período (THALLER, 1988, p. 198-199). 
A projeção da demanda ter sido subestimada ou, a de custos, sobrestimada pelo BNDES, no entanto, pode ter abaixado a estimativa dos valores de outorga. Nesse sentido, a postura conservadora adotada pelo BNDES quando feita a análise de risco pode ter deflagrado em uma taxa de desconto alta, resultando em um valor mínimo para a realização do leilão relativamente baixo (GONÇALVES et. al., 2020).

Anota-se, porém, que a despeito de qualquer das possibilidades elencadas ter ocorrido, compete à Agência Nacional de Águas, de acordo com o novo marco regulatório do saneamento, fiscalizar a contratação, bem como a execução da concessão, garantido que não tenha ocorrido um caso de winner's curse. O referido marco propôs maior enforcement no que diz respeito à atuação da agência (RITTNER, 2020).

$\mathrm{Na}$ medida em que os Municípios abarcados pelo leilão constituem uma Região Metropolitana, não houve necessidade de aprovação individual do processo licitatório, mas, tão somente, do Conselho de Desenvolvimento da Região, instituído pela Lei n. 13.089/2015, conhecida como Estatuto da Metrópole. A celeridade e segurança das licitações se baseia, nesse cenário, na estabilidade dos arranjos de governança interfederativa, ainda que, este, seja um dos principais desafios para abertura do setor saneamento básico (GONÇALVES et. al., 2020).

A perspectiva atual para o setor aponta para novos investimentos a partir da abertura de mercado, com atração de investidores e reaquecimento da economia, o que favorece a população beneficiária da prestação de serviços. Acredita-se que o leilão da Companhia de Saneamento de Alagoas (CASAL) tenha sido apenas o início da abertura a novas oportunidades de concessões a partir da modalidade licitatória em outras regiões do Brasil (RITTNER, 2020).

\section{Conclusão}

O arsenal teórico, desenvolvido a partir da aplicação da teoria dos leilões à privatização do setor de saneamento básico a partir do modelo de concessões, não conduz a um modelo mais recomendado de formatação de licitações, mas, em verdade, à necessidade de que a formatação do leilão esteja essencialmente atrelada ao objetivo perseguido pela licitação, observadas peculiaridades dos sistemas de água e esgotamento, bem como as necessidades e características locais e regionais do lugar onde virá a ser implementado.

Observa-se que, ao se descrever a teoria dos leilões, acaba-se, consequentemente, analisando como o resultado de uma licitação tende a ser influenciado pelas regras postas para o certame. Nesse sentido, tendo em vista que uma diversidade de finalidades pode ser perseguida, a conclusão básica é a de que a escolha do modelo ideal de leilão dependerá da 
finalidade principal que se quer atingir com a concessão do serviço à iniciativa privada. A definição do objetivo de uma concessão precede a modelagem do procedimento licitatório. Sendo assim, a modelagem de uma licitação deve observar como a escolha do modelo de leilão pode afetar seu resultado.

Buscou-se, a partir deste trabalho, demonstrar como conclusões teóricas do atual estágio da teoria dos leilões podem ser internalizadas para o aperfeiçoamento das licitações, em uma análise econômica dos processos licitatórios e do modelo de concessões aplicado ao setor saneamento básico. É necessário que pesquisas futuras formulem uma releitura em torno das circunstâncias que devem orientar o desenho de um processo licitatório, não somente à luz do dispositivo legal que rege a matéria, mas, também, considerando as necessidades e peculiaridades setoriais.

Pretendeu-se, com este artigo, a partir do novo marco regulatório de saneamento básico, apresentar vantagens e desvantagens da aplicação da teoria dos leilões à formulação dos processos licitatórios que abrem margem à atuação da iniciativa privada no setor, demarcando as situações em que cada um deles se torna mais recomendável e as possibilidades legais de aplicação dos diferentes tipos.

Considera-se a importância das contratações públicas para o reaquecimento da economia nacional. O maior desafio, agora, muito provavelmente será o de compatibilização da aplicação das conclusões obtidas neste trabalho, que demandam, necessariamente, a formulação de editais específicos para cada projeto e a dedicação de especialistas e autoridades de diferentes searas, com a gradual necessidade de atuação administrativa em matéria de licitações para arcar com a tendência de aumento de contratações públicas a partir do novo marco regulatório.

\section{Referências}

AGUIAR, Alex M. S. No leilão do saneamento de Maceió, os pobre de Alagoas pagam o pato. Economia Uol, 2020. Disponível em: <https://economia.uol.com.br/colunas/2020/10/09/noleilao-do-saneamento-de-maceio-os-pobres-de-alagoas-pagam-o-pato.htm>. Acesso em $21 \mathrm{de}$ outubro de 2020.

ARRETCHE, Marta T. S. Política Nacional de Saneamento: a reestruturação das companhias estaduais. In: IPEA, Instituto de Pesquisa Econômica Aplicada. Infra-estrutura: perspectivas de reorganização - saneamento. Brasília: Ipea, 1999. p. 79-108.

BANCO MUNDIAL. Serviços urbanos de água e esgotamento sanitário (A+E): desafios da inclusão e da sustentabilidade rumo ao acesso universal. Washington: World Bank Group, 2018.

Disponível

em: 
$<$ http://documents.worldbank.org/curated/en/750841521485336025/Servi\%C3\%A7osUrbanosde- $\% \mathrm{C} 3 \% 81$ gua-e-Esgotamento-Sanit $\% \mathrm{C} 3 \%$ A1rio-A-E-DesafiosInclus\%C3\%A3o-e-da-Sustentabilidade-Rumo-ao-Acesso-Universal $>$. Acesso em 16 de outubro de 2020.

BINMORE, Ken; KLEMPERER, Paul. The biggest auction ever: The sale of the British $3 \mathrm{G}$ telecom licences. The Economic Journal, v. 112, n. 478, p. C74-C96, 2002.

CARVALHO, Victor Aguiar de. O Estatuto das Estatais sob a ótica da Teoria dos Leilões: alguns aprimoramentos para a prevenção à corrupção e aos cartéis nas licitações. Revista de Dir. Público da Economia - RDPE. Belo Horizonte, ano 16, n. 64, p. 175-203, out./dez. 2018.

CORREIA, P. B.; LANZOTTI, C. R.; SILVA, A. J. Teoria dos Leilões: Formulações e Aplicações no Setor Elétrico. In: Anais do II Congresso de Inovação Tecnológica em Energia Elétrica. CITENEL. 2003. p. 711-715.

DE SILVA, Dakshina G. et al. The impact of public information on bidding in highway procurement auctions. European Economic Review, v. 52, p. 150-181, 2008.

FIANI, Ronaldo. Teoria dos Jogos. 4. ed. Rio de Janeiro: Elsevier, 2015.

FIUZA, Eduardo Pedral Sampaio; MEDEIROS, Bernardo Abreu de. A agenda perdida das compras públicas: rumo a uma reforma abrangente da lei de licitações e do arcabouço institucional.Texto para discussão/Instituto de Pesquisa Econômica Aplicada. Brasília: Rio de Janeiro: Ipea, 2015.

GIAMBIAGI, Fabio. Capitalismo: modo de usar. Elsevier Brasil, 2015.

GICO JR, Ivo T. Metodologia e epistemologia da análise econômica do direito. Economic Analysis of Law Review, v. 1, n. 1, p. 7-33, 2010.

GONÇALVES, Edson Daniel; SMIDERLE, Juliana Jerônimo; CAPODEFERRO, Morganna Werneck; ENGEL, Pedro Henrique. Nova era do saneamento à vista (apesar dos percalços). Blog do Instituto Brasileiro de Economia, FGV, 2020. Disponível em: $<$ https://blogdoibre.fgv.br/posts/nova-era-do-saneamento-vista-apesar-dos-percalcos $>$. Acesso em: 22 de outubro de 2020.

GONÇALVES, Lara Sartorio; DA SILVA, Caroline Rodrigues. Pandemia de Covid-19: sobre o direito de lavar as mãos e o" novo" marco regulatório de saneamento básico. Revista Científica Foz, v. 3, n. 1, p. 71-92, 2020.

KLEMPERER, Paul. Auctions: Theory and Practice. Princeton: Princeton University Press, 2004.

KRISHNA, Vijay. Auction Theory. 2. ed. San Diego: Elsevier, 2010.

MATOSO, Flávia. Teoria dos Leilões: uma abordagem para a promoção da defesa e da advocacia da concorrência, V Prêmio SEAE - Defesa da Concorrência e Regulação Econômica, 2010, p. 475-476. Disponível em: <http://www.seae.fazenda.gov.br/premio- 
seae/edicoes-anteriores/edicao-2010/v-

premio-seae-

2010/Estudantes_2_lugar_Flavia_Diagramado.pdf $>$. Acesso em 22 de outubro de 2020.

MILGROM, Paul. Auction theory. In: Advances in economic theory: Fifth world congress. Cambridge: Cambridge University Press, 1987. 52 p.

MOTTA, Ronaldo Seroa da. Questões regulatórias do setor de saneamento no Brasil. Notas técnicas. n. 5. Rio de Janeiro: Ipea, 2004. 28 p.

NOZAKI, Victor Toyoji de. Análise do setor de saneamento básico no Brasil. 2007. Tese de Doutorado. Universidade de São Paulo. 110 p.

PITASSI, Sandro Lucio Barbosa; FERREIRA, Aldo Pacheco. A atuação do Poder Judiciário na concreção das políticas públicas de saneamento básico: possibilidades e limites. Saúde em Debate, v. 43, p. 111-125, 2020.

RITTNER, Daniel. Análise: sucesso em leilão de Alagoas representa virada de página no saneamento. Valor, Brasília, 2020. Disponível em: $<$ https://valor.globo.com/empresas/noticia/2020/09/30/analise-sucesso-em-leilao-de-alagoasrepresenta-virada-de-pagina-no-saneamento.ghtml>. Acesso em 22 de outubro de 2020.

SANTOS, Angela Moulin Simões Penalva; VASQUES, Pedro Henrique Ramos Prado. Política urbana no contexto federativo brasileiro: um avanço normativo na gestão dos aglomerados urbanos. Revista Direito da Cidade, v.7, n.4, 2015. p. 1771-1790.

SANTOS, G. R.; KUWAJIMA, J. I. ODS 6 - assegurar a disponibilidade e gestão sustentável da água e saneamento para todas e todos. In: SILVA, E. R. A.; PELIANO, A. M.; CHAVES, J. V. (Coord.). Cadernos ODS. Brasília: Ipea, 2019. 40 p.

SANTOS, Gesmar Rosa dos; KUWAJIMA, Julio Issao; SANTANA, Adrielli Santos de. Regulação e investimento no setor de saneamento no Brasil: trajetórias, desafios e incertezas. Texto para discussão 2587, IPEA, Rio de Janeiro, 2020. 70 p.

SILVA. A.H.L. Preço de reserva sigiloso e licitações públicas. Monografia vencedora do terceiro lugar do Prêmio de Economia e Contabilidade do Setor Público do Tesouro da Fazenda, $2017 . \quad$ Disponível em: <http://www.tesouro.fazenda.gov.br/documents/10180/137713/Premio2011_Tema_2_3.pdf.>. Acesso em 20 de outubro de 2020.

SOUSA, Ana Cristina Augusto de; COSTA, Nilson do Rosário. Ação coletiva e veto em política pública: o caso do saneamento no Brasil (1998-2002). Ciência \& Saúde Coletiva, v. 16, n. 8, 2011.p. 3541-3552.

THALER, Richard H. Anomalies: The winner's curse. Journal of Economic Perspectives, v. 2, n. 1, p. 191-202, 1988.

VASQUES, Pedro Henrique Ramos Prado. Saneamento básico: uma avaliação sobre a atuação dos setores público e privado no contexto de novas proposições regulatórias. Geo UERJ, n. 36, p. 48413, 2020. 
VICKREY, William. Counterspeculation, auctions, and competitive sealed tenders. The Journal of finance, v. 16, n. 1, p. 8-37, 1961.

WILSON, Robert. Auction theory. The New Palgrave. MacMillan, London, 1987.

WWAP - WORLD WATER ASSESSMENT PROGRAMME. The United Nations World Water Development Report 2018: nature-based solutions for water. Paris: UNESCO, 2018. $139 \mathrm{p}$.

Data de recebimento: 06.05.2021

Data de aprovação: 22.07.2021 